\title{
Difficult or Delayed Separation
}

National Cancer Institute

\section{Source}

National Cancer Institute. Difficult or Delayed Separation. NCI Thesaurus. Code C133633.

Problem associated with users experiencing difficulty or delay with detachment or separation of the device. 